\title{
III Congreso Internacional Virtual de Educación Literaria
}

\author{
Carmen María Sánchez Morillas \\ Asociación Española de Comprensión Lectora \\ Carmensnchez9@gmail.com
}

El pasado mes de diciembre se celebró en la modalidad virtual el III Congreso de Educación Lectora (CIVEL) organizado por la Universidad de Málaga y los miembros de la Asociación Española de Comprensión Lectora (AECL). Entre las conferencias celebradas destacan las aportaciones de Elena Jiménez, presidente de la AECL, Antonio Díez Mediavilla, Aldo Ocampo González, Enrico Bocciolessi, Yrene Natividad Calero o Antonio García Velasco.

El Congreso comenzó con la conferencia inaugural, "Educación Lectora" de Elena Jiménez Pérez, profesora del Departamento de Didáctica de Lengua y Literatura de la Universidad de Granada, y presidente de la AECL. En su exposición la profesora realizó un breve análisis del concepto de educación lectora en los textos legales educativos desde finales de la dictadura franquista, pasando por los primeros años de la democracia, hasta nuestros días. Así se repasaron las ocho leyes educativas, desde la LGE de 1970 hasta la más reciente LOMCE de 2013. Para Jiménez ninguna ley describe o trata de manera directa el concepto de educación lectora; solo encuentra ciertas puntualizaciones en la ley de 1970 sobre el placer de leer, o las matizaciones legales de la Ley del 10/2007 de Lectura donde se resalta el concepto de lectura y libro por igual. Si bien la educación lectora, apunta la presidenta de la AECL, está recibiendo más atención desde las instituciones educativas oficiales, todavía queda un camino largo por recorrer para llegar a los niveles educativos, sobre todo de comprensión lectora, comparables a los de Finlandia.

Los datos y conclusiones expuestos por Jiménez completan lo expuesto por Antonio Díez Mediavilla, de la Universidad de Alicante, en su aportación: "Algunas precisiones sobre la evaluación de la competencia/comprensión lectora". Díez observa y analiza los instrumentos de evaluación empleados para valorar el rendimiento de los aprendizajes lectores; denota ciertas contradicciones que presentan las pruebas tradicionales de evaluación de comprensión lectora: preguntas de comprensión, reflexión sobre estructuras textuales...Como alternativas a esta tipo de instrumentos deben incluirse categorías de evaluación tales como la tipología textual o la empatía y complicidad que el lector muestra sobre el texto, o propuestas didácticas donde se produzcan situaciones pragmática de lectura.

Desde la Universidad de Valparaíso, Chile, el profesor Aldo Ocampo González trataba la relación existente entre el derecho a leer y a la lectura en las sociedades latinoamericanas en el siglo XXI. En "Democracia lectora, disenso social y ciudadanías en disputa" se expone el desafío crucial de la lectura como derecho para aquellos alumnos con necesidades educativas especiales en el contexto latinoamericano, además de repasar las diferentes metodologías que se aplican. En último lugar, Ocampo aporta un análisis sobre el desarrollo de la democracia lectora y la facilitación del discurso escrito. 
Enrico Bocciolesi, desde la Univesitá degli Studi e Campus, apostó por un análisis detenido por el concepto del "Blendig Reading" o cómo se produce un conflicto entre las redes digitales, los modelos lectores que producen, y un concepto más tradicional de lectura asociado al libro físico.

Merece una mención especial la exposición, "El fomento de la lectura como base para la competencia lectora en la escuela", de Yrene Natividad Calero, presidente de la Asociación Internacional de Promotores de la Lectura. Dicha aportación se centró en la revalorización del nuevo interés de la lectura como elemento transversal en los sistemas educativos, no solo en el área de comunicación. La autora contextualizó parte de su trabajo en el comentario del Plan Lector en Perú y la urgente necesidad de que los maestros formen como lectores a sus alumnos.

El ciclo de conferencias se cerró con la participación de Antonio García Velasco, profesor de la Universidad de Málaga. García expuso, de una manera didáctico-práctica, una secuenciación de ejercicios, creados mediante una aplicación informática, cuyo objetivo era demostrar cómo se puede preparar la lectura, comentar y leer.

En cada jornada, además de las conferencias plenarias, se llevaron a cabo más de 30 comunicaciones de diferentes temáticas. Desde un punto de vista más general, se presentaron comunicaciones que versaron sobre el fomento de la lectura o el tratamiento del hábito lector en la familia y en la educación primaria, la necesidad de un proyecto lingüístico en los centros educativos, o cómo se desarrolla la comprensión lectora en alumnos con necesidades educativas especiales.

Además, la comprensión lectora fue también objeto de estudio y de evaluación, como revelaron las comunicaciones sobre los baremos que establece el informe PISA o la formación que poseen los docentes sobre la lectura y el proceso lector.

Si tenemos en cuenta un análisis social de instituciones públicas, la existencia de las bibliotecas como entornos de fomento lector y la aparición de las bibliotecas virtuales como elementos propios del aula fueron motivo de estudio incluidos en este congreso.

La presencia de las nuevas tecnologías y su fuerte influencia se abordaron en ámbitos de discusión como: la utilidad de los booktráiler o los booktuber, como herramientas de fomento de la lectura; el desarrollo de la comprensión lectora mediante el uso de estas tecnologías y textos clásicos de la literatura; o la relación que se establece entre lectura, ocio e internet.

Desde la enseñanza de lenguas se trataron temas como el hecho de la comprensión lectora y el aprendizaje de una segunda lengua o la comprensión lectora y la relevancia que posee en los textos traducidos, además del empleo de recursos tecnológicos bilingües.

Todas las conferencias plenarias, así como una selección de comunicaciones, se editarán en el volumen Educación lectora, de próxima publicación. 